\title{
The role of physical activity in prevention and treatment of peripheral vascular disorders
}

\author{
Jarosław Pasek', Agata Stanek², Grzegorz Cieślar² \\ 'University of Jan Długosz in Częstochowa, Faculty of Health Sciences, Poland \\ ${ }^{2}$ Department of Internal Medicine, Angiology and Physical Medicine, Faculty of Medical Sciences in Zabrze, \\ Medical University of Silesia in Katowice, Poland
}

\begin{abstract}
Peripheral vascular diseases constitute one of the most significant medical and social problems. Physiotherapy plays an important role among and in addition to various treatment modalities. Physiotherapy for vascular disorders applied in vessel disease treatment primarily consists of reasonable and regular exercises and activities, and selected physical procedures. The review paper presents current data concerning the most commonly applied exercises and physical procedures in selected peripheral vascular diseases.
\end{abstract}

Key words: vessel diseases, physiotherapy, treatment

Acta Angiol 2020; 26, I: 19-27

\section{Introduction}

Vascular diseases impair the quality and comfort of life of patients. Epidemiologic data indicate that $20-50 \%$ of adult population suffer from venous and arterial vascular diseases of various etiology [I]. The higher morbidity rate is characteristic for women rather than men. Peripheral vascular diseases are divided into organic (e.g. peripheral artery occlusive disease, Buerger's disease, lower limb varicosis) and angioneurotic disorders (e.g. Raynaud's syndrome) [2].

Each year the number of publications in the international medical journals concerning vascular disease treatment increases. The level of current researches is very high. They enable a better understanding of the etiopathophysiology of vessel system disorders, and they also present the new ways of treatment of these patients $[3,4]$.

\section{The principles of primary prophylaxis in patients for arterial diseases}

The major purpose of primary prophylaxis of vascular disorders is the education of the society about the causes and consequence of the disease, about risk factors (arterial hypertension, obesity, diabetes etc.) and their treatment. This includes education about proper diet and nutrition including a high amount of proteins, vegetables and fruits. The positive attitude towards a healthy lifestyle (more walks, bicycle riding, swimming) by an adequate understanding of physical activity is the integral element. Common ailments should be avoided $[5,6]$.

For secondary prophylaxis, one has to combat risk factors and introduce modification into a present lifestyle. All patients with BMI index $>25$, patients not following their diets, patients with diagnosed arterial hypertension, patients with increased blood glucose or total cholesterol level and smokers are recommended to initiate measures of secondary prophylaxis $[7,8]$.

In the case of patients suffering from peripheral artery disease (PAD) with symptoms of intermittent claudication, one aim of physical therapy is to create collateral circulation providing ischemic areas with the adequate blood supply. One of the methods to achieve this is to increase arterial tension increase in blood vessels proximal to the place of obstruction, and simultaneously reduce vascular resistance in segments

Address for correspondence: Jarosław Pasek, University of Jan Długosz in Częstochowa, Faculty of Health Sciences,

ul. Armii Krajowej 13/I5 4I-200 Częstochowa, e-mail: jarus_tomus@o2.pl 
distally from the place of obstruction. In the case of people with a sedentary lifestyle, the increase of physical activity in basic activities of daily living (ADL) will provide a major benefit. This should be initiated after the baseline determination of individual risk and patient's competence and condition. This concept is defined as a functional physical activity. It includes walking, short distance bicycle riding, stairs climbing instead of taking an elevator, or ordinary garden activities $[9,10]$.

It is essential to mention that patients with critical limb ischemia (CLI) do not qualify for exercise training. CLI in patients with lower limb PAD is defined, as chronic ischemic pain occurring during rest, lasting for more than two weeks, or as ischemic lesions in the form of foot ulceration or necrosis. CLI is associated with a high risk of limb loss and occurrence of vascular episodes in the form of myocardial infarction and cerebrovascular accident [1 I, 12].

An excellent exercise unit in case of Fontaine's stage I or II chronic lower limb ischemia is walking training aimed at increasing blood flow to the leg and thereby recruiting collaterals. Additionally, regular exercises extend the period of intermittent claudication. Treatment of patients with claudication includes not only extension of claudication distance, but also the countermeasures against multiple ischemia incidents and blood resupply to limbs. In addition, it stimulates the gastrocnemius muscle pump thereby increasing venous blood outflow [13, I4].

\section{The principles of primary prophylaxis in patients for venous diseases}

Besides aforesaid physical activity, the following factors play a significant role in the prophylaxis of chronic venous disorders and lymphatic oedema: keeping proper body mass and following a diet, avoiding obstructions, tight clothes, high heels, hot baths, sauna and sunbathing. It is crucial to drink at least 2,5 litres of neutral fluids and rest with lower limbs placed $15 \mathrm{~cm}$ higher than the heart level [15]. Patients with lymphatic oedema have to avoid therapeutic procedures, blood pressure measurements and blood collection from the limb affected with lymphoedema [6, I6].

Working patients need to take care of the adequate, ergonomic place of work (using proper bolsters, avoiding prolonged standstill, and if possible, doing exercises aiming at sural region mobility (bending of dorsum/sole of feet, standing on tiptoes/heels in sedentary position, mark time while in sedentary position) $[17,18]$.

In primary prophylaxis of chronic venous disorders, it is also recommended to wear compression stockings, especially in case of those patients, who work mostly in sedentary/standing positions, and those, whose family history revealed similar venous disorders $[19,20]$.
In primary prophylaxis or venous disease, it is also recommended to place limbs higher (bolster during sleep, sitting etc. for passive congestions reducing oedema and pain), and to avoid excessive, standing or sedentary position [5, 6].

Currently, the term travel syndrome has been coined - it is one of the most significant risk factors of venous thromboembolic disease. With long-term plane travels, however, it can occur during long car, train or bus travels. One should bear it in mind while planning long travels. Travellers need to wear loose clothes not compressing lower limbs and waist, drink appropriate amount of fluids and often tighten their leg muscle as well. Whereas in case of people with at least one venous thromboembolism risk factor, who are to travel longer than 8 hours, it is recommended to wear low-level compression stockings or/and take a single prophylactic dose of low molecular weight heparin around 2 hours before travel [2I]. Moreover, bed rest constitutes one of the major causes of the high risk of venous thromboembolism development; thus, the bed rest period should be minimised taking into consideration the patients' clinic condition. Besides minimising immobility, other physical methods play a significant role in primary thromboprophylaxis: graded compression stocking and intermittent pneumatic compression [22, 23]. Anticoagulant primary prophylaxis has to be used not only at surgical wards but also at non-surgical ones and in ambulatory treatment. It was proven that the venous thromboembolism risk profile is as high in hospitalised patients as in patients treated at their homes [24].

\section{Diagnostics evaluation before initiation} of physiotherapy needs in lower limb PAD

I. Exclusion of critical limb ischemia.

2. Diagnosis of comorbidities not allowing to perform exercise training.

3. Standardized evaluation of patient's performance as a baseline exam.

March test - consists in marking the distance a patient is able to cover without typical ischemic pains. A patient under physiotherapist's assistance should move in a pace 120 steps per I minute ( 3 steps per second). During tests, the attention is paid to the fact when and where limb pain occurs, and if a patient weighs down both legs equally $[25,26]$.

The results should be classified into three groups according to Waibel:

I. Minor disorders of muscular blood flow in limbs, pain does not occur after three-minute exercise.

2. Medium disorders of muscular blood flow in limbs, pain occurs after one up to three minutes of exercise.

3. Severe peripheral disorder, pain occurs in the first minute of exercise. 
Older people should do 60-90 steps per minute, because other post-exertional symptoms may occur, such as dyspnoea or stenocardial pain. The trail should not be performed in IV class of PAD. Other functional assessment methods of patients with PAD includes ankle-brachial index $(A B I)$ and Ratschow test [25]. During $A B I$, the measurement is carried out in supine position; by means of Doppler probe (so-called "Doppler blind probe") blood flow is located in the dorsal artery of foot and posterior tibial artery. Having pumped up sphygmomanometer bladder placed above lateral malleolus and impeded blood flow in the artery, the pressure is released in the cuff. The moment the blood flow starts again in the artery is noted as the systolic blood pressure. The procedure is repeated for both limbs, and then $A B I$ is calculated by dividing higher malleolar pressure value by higher brachial systolic blood pressure (the pressure should be measured on both limbs, and the higher one should be applied in calculations). The normal $A B I$ index range is $0,9-1,15$. $A B I$ below 0,9 is the symptom of stenoses. In patients with diabetes or renal failure, $A B I$ may be falsely higher (over 1,3 ) as a result of blood vessel calcification - these cases require toe-brachial index $[27,28]$.

Ratschow test allows determining if the lower limb arterial lumen or iliac girdle is occluded. Patient in supine position bends and straightens feet with lower limbs raised up vertically - around 40 moves per minute. If one foot or both turns pale, or sural pain occurs, it proves ischemia. In verticalisation (or sedentary position) reactive hyperaemia ( $>15 \mathrm{~s})$ and delayed superficial vein ingurgitation on feet $(>20 \mathrm{~s})$ are observed [29].

\section{Physiotherapy in selected vascular diseases}

\section{Kinesiotherapy}

Exercise training basic form of best medical therapy (BMT) for vascular disorders [30]. It may be treated as a basic therapeutic method replacing other, more costly treatment methods [3I].

\section{Lower limb peripheral artery disease (PAD)}

Lower limb PAD requires exercise training. Patients up to 60 do 120 steps per minute, $60 \pm 60$ steps per minute, first 20 minutes, then 45 minutes $2-3$ times/ /day. The distance should be $2 / 3$ of claudication distance, thus one avoids the distance preceding pain. Recommended period of exercises - at least 20 weeks. Standing on tiptoes up to 30 repetitions 2-3 times/day and tiptoe push-ups are also beneficial. Their aim is the additional thigh and buttock muscle overloading [2, 14]. What is more, stair climbing, cycloergometer riding and swimming are recommended [32]. Despite the proven increase of endurance and march capacities and patients' general condition improvement, march training influences also biochemical and physiological organism mechanisms. Its positive impact on the fibrinolytic activity of patients with chronic limb ischemia has been proved [33]. Moreover, kinesiotherapy leads to better oxidative saturation of arterial blood, reduced concentration of LDL- cholesterol fraction in blood, and improvement of carbohydrate metabolism in patients with coexistent diabetes. March training results also in muscle morphology changes, walking economisation, changed pain perception, and, which is the most important for patients, it actually prolongs the claudication distance and improves general fitness [34, 35].

By peripheral occlusions, circulation disorders concern in major cases the most peripheral limb parts (hands and feet). Blood flow in cutaneous vessels can be improved by lower placement of limbs. Sleeping with one limb lower, stretched beyond a bed at an angle of $30^{\circ}$ supported by something soft brings relief. Raising the head of a bed or performing Ratschow and Buerger's exercises are also beneficial [36]. The exercises consist of alternate limb raising and lowering, causing active congestion and ischemia of muscles by changing the position. Another Ratschow exercise requires a patient in the supine position to lift lower limb at an angle of $90^{\circ}$ and grab thighs simultaneously with both hands in posterior region of the knee; then a patient performs rotation in crurotalar joints till first exhaustion symptoms (2-5 minutes). Next steps are limb lowering beyond a bed ( $2-5$ minutes), resting in supine position and repetition of rotation in joints. The exercises should be performed in the morning and in the evening $[37,38]$. In case of peripheral vessel diseases with intermittent claudication as the only symptom, a patient should not be recommended to refrain from walking. A patient has to perform moderate and thoroughly planned general and limb exercises, spend I hour walking to prevent amyotrophy. Limiting physical exercises, walking in particular, is a big mistake $[15,16]$.

Bürger's exercises are variation of above exercises. A patient in supine position lifts one's lower limbs at an angle of $45^{\circ}$ and bends feet and toes rhythmically up to 3-4 minutes (up to endurance limit); then, a patient sits with lowered limbs for 3-4 minutes (reactive congestion). Next, a patient rests in supine position up to 3-4 minutes and repeats the exercise. Rhythmical changes of positions enhance blood outflow and inflow to limbs, having a positive effect on pain symptom intensity by vessel peristalsis. The exercise cycle should last $0,5-1$ hour, 2-3 times/day. Additionally, one can perform bicycle crunch in ambulatory conditions. Cycloergometer training, outdoor walking, aerobics and benign jogging may also be a part of active rehabilitation. Besides those 
aforementioned physical activities, it is also recommended to stand on tiptoes/heels, climb stairs (patients with competent cardiovascular system) $[2,36]$.

\section{Chronic venous disorders and lower limb deep venous thrombosis}

In venous diseases, kinesiotherapy should include active lower limb exercises, enhance blood outflow as a result of muscle pump operation, isometric exercises and pelvic girdle exercises. Apart from that, everyday walks, bicycle or cycloergometer riding or swimming play significant roles as well [25].

The easiest form of exercises is alternating dorsal bending and plantar extension of feet performed twice a day, especially in case of sedentary lifestyle [I, 39].

In venous diseases, one should refrain from long sedentary positions with lowered lower limbs, and folding legs; while resting limbs should be placed higher than the rest of the body [40]. Patients are also recommended to avoid exertional exercises requiring abdominal press such as mountain biking, weightlifting, tennis on a hard surface, squash and other physical activity forms significantly overloading sural muscles and requiring sudden accelerations [25].

Early patients' mobilisation is also very important in patients with lower limb deep venous thrombosis. It has been proven that early mobilisation of patients with simultaneous compression therapy appliance does not increase the risk of pulmonary thromboembolism, but reduces pain and limb oedema, and improves the quality of patient' life and venous vessel fibrinolysis. If ballooning clot/thrombus is not diagnosed, a patient should be mobilised within 24 hours, and compression therapy should be applied during mobilisation $[20,4 I]$. High levels of physical activity at one month were shown to be associated with reduced severity of post-thrombotic symptoms during the subsequent 3 months [42].

\section{Lymphoedema}

Lymphoedema is characterised by accumulation of interstitial fluid in skin and subcutaneous tissue as a result of lymphoid system dysfunction, containing e.g. water, proteins, erythrocytes, lymphocytes, islet cells, cytokines and keratinocytes, fibroblasts and endothelial cells. It leads to chronic inflammation process and results in fibrosis of the skin and subcutaneous tissue $[16,43]$. Brunner distinguishes fives stages of lower limb lymphatic oedema [25].

I. Benign oedema of feet and lower leg occurring at the end of a day, resolving spontaneously after lifting a limb.

2. Whole-day oedema resolving spontaneously after night with positive Stemmer sign (skin fold thickening above the second toe, skin hard to lift).
3. Permanent oedema, not resolving after limb evelating.

4. Permanent foot-deforming oedema, often complications of skin inflammation, (erysipelas, eczema, lymphatic fistulas).

5. Elephantiasis - large foot-deforming oedema with skin thickening, muscle lesions (dystrophy), compromising functioning of a limb.

Lymphatic oedema is prone to accretion without adequate treatment. In lymphatic oedema treatment, complex decongestive therapy (CDT) plays a major role. It was proven that CDT appliance is much more efficient than monotherapy appliance. The proper appliance of CDT therapeutic element combination leads to oedema reduction, enables sustaining the therapy effects and limits the occurrence of complication. The essential parts of complex decongestive therapy constitute kinesiotherapy, compression therapy and manual lymphatic drainage (MLD) [6, 44].

Physical activity constitutes a significant addition to CDT. It is aimed at mobilisation of myoarticular pump and better reabsorption of fluids at vessel capillary level. Recommended kinesiotherapy forms, similar as in patients with chronic venous disorders, are: walks, endurance march, jogging, nordic walking, bicycle riding on flat terrains, hiking, dancing, swimming and cross-country skiing. Patients with lymphatic oedema should do exercises and breathing exercises, especially diaphragmatic breathing. One should bear in mind that exercises facilitating lymph outflow have to be performed in the lymph drainage direction. Both, in chronic venous disorders and lymphatic oedema the following kinesiotherapy forms are contradicted: exertional forms requiring abdominal press forms overloading sural muscles and requiring sudden accelerations [12, I3].

It should be highlighted that physical activity gives better results with simultaneous compression therapy by bandages or other compression materials. Otherwise, movement and exercises may intensify lymphostasis and increase oedema. Swimming or water gym are exceptions - water environment takes the role of compressor [II,I3].

\section{Compression therapy}

Compression therapy is found to be golden standard in chronic venous disorder and lymphatic oedema treatment. The mechanism of beneficial compression therapy influence is connected with lowering of venous blood pressure by reduction or elimination of reflex, facilitation of muscle pump functioning (lowering of march pressure), decrease of venous diameter and restoration of venous valves by drawing cusps nearer, reduction of congestion, improvement of lymphatic 
drainage by compression of subcutaneous tissues (increase of intratissued pressure, increased oedemic fluid absorption, reduction of protein amount in tissues, which may can to regression of lipodermatosclerosis lesions) [45].

Because of the fact that compression therapy has direct influence only on hydrostatic intratissued pressure, but it does not influence oncotic pressure (i.e. osmotic pressure of protein colloid), it is highly possible that discontinuation or end of compression will cause fast oedema recurrence [13].

Compression therapy indications include chronic venous incompetence (in venous ulceration), thrombosis of superficial and deep veins, lymphatic oedema, post-traumatic oedema, erysipelas, vessel inflammation oedema, after venous sclerotherapy or surgical treatment of varices; whereas, the compression therapy contra-indications are the following severe advanced peripheral vessel sclerosis (III or IV stage according to Fontain class) $A B I<0,8$ by high compression, absolute $\mathrm{p} / \mathrm{w}-\mathrm{ABI}$ $<0,6$, decompensated circulation incompetence, skin lesions with characteristic intense exudate, sensation disorder (advanced peripheral neuropathy), hypersensitivity to compression stocking material $[20,25]$. It can take the form of bandages, compression textiles or intermittent pneumatic compression $[46,47]$.

Compression products (knee-length socks, stockings and pantyhose) are manufactured in four compression categories [47]:

- I compression level (20-30 mm Hg): anti-thrombotic prophylaxis at-risk groups, venous disorder prophylaxis, venous disorder treatment in $\mathrm{Cl}-\mathrm{C} 2$ stage, I stage of lymphatic oedema;

- II compression level (30-40 mm Hg): thrombotic inflamation of veins, after invasive procedures (sclerotherapy or surgical treatment of varices), ulceration recurrence prophylaxis, C3-C4 stage (oedema, trophic lesions), II and III stage of lymphatic oedema;

- III compression level (40-50 mm Hg): advanced trophic lesions in chronic venous incompetence, chronic venous ulceration, varices of large venous trunks with severe oedema, III and IV stage of lymphatic oedema;

- IV compression level (50-60 mm Hg): irreversible venous oedema, venous ulceration in post-thrombotic syndrome, severe post-thrombotic syndrome, IV and $V$ stage of lymphatic oedema.

Two types of compression are distinguished i.e.: flexible and inflexible compression. Flexible compression is generated by bandage with a medium or high level of tensility and compression products, and it is independent with regards to muscle activity but it creates high static pressure. Thus, they should not be worn overnight [48]. On the other hand, inflexible compression is created by non-tensile or little tensile bandages or layered compression products. Inflexible compression is not recommended in case of inactive patients [49].

Pneumatic massage is a type of therapy using special, sequentially inflated compression cuffs i.e. pressotherapy. Pressotherapy consists of simultaneous or alternate tissue massage by means of compression cuffs with overlapping chambers. The method facilitates the treatment of patients with lymphatic and venous incompetence. It is also applied in upper limb oedema in female patients after mastectomy and anti-thrombotic prophylaxis. The single procedure should last around 60 minutes (dependent on the stage of disease), be sequential (filling of next chambers from circle to nearer limb parts) and performed once a day for 5-6 days/ /week. After pneumatic drainage (active compression) passive compression (bandaging, compression products) should be applied $[25,50]$.

\section{Manual lymphatic drainage (MLD)}

Major MLD's purposes are the following: increasing lymph outflow, especially from stasis areas, mobilisation of lymphatic vessels and flow intensification through lymph nodes, stimulating new lymph connection development between outflow areas i.e. anastomoses, and analgesic and regeneration activity [5I].

MLD consists of stimulation of lymphatic system by special movements causing forced, but benign, lymphatic outflow. MLD requires three techniques: stroking, rubbing and pressing.

Lymphatic massage is based on four basic Vodder's strokes: "stationary circle", "rotary", "pump" and "scoop". Massage strength depends on the area of the body. It is carried out by outstretched hand placed flat parallel to a patient's skin without creams or oils. The procedure always begins with neck where two lymphatic trunks converge with venous system, then trunk quarters free from oedema adjacent to oedematous limb, and oedematous area at the end. The general MLD principle is drainage of the most proximal segment in order to lead there oedema from the lower segment. And, for instance, drainage in women after right-side mastectomy with axillary lymphadenectomy is conducted in the following sequence: neck, upper trunk quarter at non-operated left side, upper trunk quarter at operated right side, upper limb at operated right side starting from shoulder to arm, forearm, and, eventually, hand $[25,52]$.

MLD's indications include lymphatic oedema (primary and secondary), venous oedema, post-traumatic oedema, lipid oedema, oedema as a result of lack of physical activity, oedema in arterial circulation disorders, chronic abacterial inflammatory oedema, 
idiopathic oedema. MLD's contra-indications are the following active inflammations (risk of septicaemia), active neoplasm processes, lymph node metastases, NYHA III-IV class of circulation incompetence; whereas local contra-indications of MLD include: in neck region - hyperthyreosis, in abdominal region - pregnancy, menstruation, non-specific enteritis, in limb region thrombophlebitis. MLD procedure should be always performed with compression therapy $[52,53]$.

\section{Physical procedures in selected} peripheral blood vessel diseases

Physical procedures are a significant part of complex blood vessel treatment. Hydrotherapeutic procedures in the form of bath or aqua massage should be mentioned here. Baths should be taken in cool or lukewarm water $\left(25-33^{\circ} \mathrm{C}\right)$. Cold constricts venous vessels massaging them gently. In some cases of lymphatic oedema (contraindications: active skin and subcutaneous tissue inflammation) rotary massage of lower/upper limbs is beneficial. Whereas, aqua massage is the special type of massage carried out during bath by applying high-pressure underwater spray of various temperatures [54].

Movement in water has a positive effect not only on the heart, but also on blood vessels. Impact of pressure and water stream leads to blood vessel massage, cardiac blood circulation and lymph circulation improvement. Faster blood circulation leads to better oxygen and nutrition supply of tissues and organs, and fitness/ /endurance improvement $[32,55]$. Water compression in particular body regions, so-called "water compression therapy", reduces venous vessel diameter and capillary permeability, improves blood outflow from limbs, and strengthens vascular walls (prevents oedema and lymph stasis) [32].

The most common procedures in a spa treatment of this group of patients are carbonic acid baths: dry or gas with natural or synthetic $\mathrm{CO}_{2}$. Carbon dioxide permeating through the skin has a direct impact on capillaries and axon reflex of skin arterioles causing capillary and bigger blood vessel vasodilation. It enhances the cardiac activity and reduces arterial blood pressure. Bath is applied in patients with functional arterial circulation disorders, capillary circulation disorders, arteriosclerosis peripheral blood vessel diseases, and I and II class arterial hypertension [54, 56].

Other forms of complex baths are radium water baths. Their appliance causes peripheral arterial vasodilation, reduction of arterial pressure, toning of the autonomic nervous system, a decrease of blood viscosity. Main indications include:peripheral vessel diseases and I and II class arterial hypertension [54, 56].

Peloid baths are another optional procedure for patients with peripheral vessel diseases. This therapy uses the natural properties of organic-mineral substances created in geological processes, so-called peloids. Peloids mixed with water create paste with therapeutic properties. Peloid procedures consist of simultaneous, gradual and steady tissue overheating and therapeutic influence of organic elements in peloid - mainly humin acids.

Both mechanisms lead to small vessel vasodilation and tissue hyperaemia. The procedures are applied in arteriosclerosis peripheral blood vessel diseases, Buerger's disease and venous ulceration of legs [42, 54].

One of the most commonly applied termotherapeutic procedures in vessel diseases are paraffin procedures in the form of compresses and wraps. Beneficial effects of the procedures are connected with the increase of blood flow. Paraffin procedures are applied usually in functional peripheral vessel diseases. The characteristic symptoms of the procedures are vessel reactions (local and general) and blood vessel performance according to Dastre-Morat law. However, one should bear in mind that termotherapeutic procedures are forbidden in patients with cardiac incompetence and arterial hypotension, which sometimes occur together with peripheral vessel diseases [54, 56].

Electrotherapeutic procedures are conducted mostly by means of direct current (galvanism), which reduces smooth muscle tension and widens their lumen as a result of current flow between two electrodes placed along peripheral arteries (applied in limb circulation disorders), and iontophoresis consisting in delivery of ionised medicine molecule through skin to tissues as a result of direct current flow (Bürger's disease and Raynaud's syndrome). Procedures using alternating current with low and medium frequency $(50-5000 \mathrm{~Hz})$ e.g. diadynamic therapy - Barnard current, electrostimulation - TENS, high voltage electrostimulation, Träbert current - Ultra Reiz, Nemec interference current, stimulating neuromuscular system with heat properties. They are applied mainly in the treatment of peripheral blood flow in Bürger's disease and Raynaud's syndrome, lower leg venous ulceration and vascular pain. High-frequency currents (e.g. low- and microwave diathermy) are also applied in Bürger's disease and venous and lymphatic peripheral circulation disorders [54, 56].

Ultrasounds constitute another physical treatment method. The essence of their therapeutic impact is connected with heat and mechanic effect (micromassage). It causes vessel vasodilation (by direct heat activity and release of histaminelike substances), activity reduction of sympathetic nervous system and stimulation of tissue regeneration process. Ultrasounds are widely applied in treatment of Raynaud's syndrome, Bürger's disease and lower leg venous ulceration $[54,56]$. 
Light therapy procedures are applied in peripheral vessel diseases, particularly in order to achieve local hyperaemia (tissue overheating - heat erythema), and blood microcirculation as a result. Additional procedures lead to microcirculation biostimulation, which enhances regeneration of damaged blood vessels, improves local circulation and rheological properties of blood. This therapeutic effect is observed mainly during low-energy light therapy by LED diodes, and polarised light therapy. In angiology, light therapy is used mainly in treatment in lower leg venous ulceration and arteriosclerosis lower limb blood vessel diseases [57, 58].

In the description of physiotherapeutic procedures in blood vessel diseases, one should not omit the developing area of physical medicine applying an alternate magnetic field. Clinical experience of authors in the appliance of magnetotherapy, magnetostimulation and magnetotherapy in treatment of skin diseases, vessel diseases and their complications, proves the therapeutic effects of the treatment e.g. in diabetic foot, lower limb venous and arterial ulceration, and Bürger disease. The basis of biological effects of these therapies is the influence of electrodynamic and magnetomechanic phenomena, and ion cyclotron resonance, on widely perceived cell metabolism. It results in acceleration of electrolyte exchange between a cell and its environment, increase in mitotic activity, antimutagenic effect, growth in enzyme activity and increase in ATP and DNA synthesis. At tissue level, one observes improvement of peripheral blood microcirculation and increase in activity and excitability of nerve fibres with angiogenesis stimulation. Nevertheless, it should be bear in mind that the severe patient's condition and limb circulation disorders require careful physical treatment appliance taking into consideration the patient's current condition and contraindications [59-6I].

\section{Conclusion}

Blood vessel diseases result in lower quality life of patients, disability, and even life-threatening complications. Although diagnostic methods have been improved, factors of their occurrence examined, surgical methods developed and new medicines introduced, vessel diseases constitute a severe medical problem, and physiotherapy still plays an essential role in prophylaxis and peripheral vessel disease treatment. Physiotherapy is particularly important in rehabilitation in the last stage of treatment leading to optimal patient's condition.

\section{Conflict of interest}

None.

\section{References:}

I. Wu Y. Construction of the vessel-collateral theory and its guidance for prevention and treatment of vasculopathy. Front Med. 20I I; 5(2): I |8-122, doi: 10.1007/s I |684-0 I I-0I40-z, indexed in Pubmed: 216956/4.

2. Menard JR, Smith HE, Riebe D, et al. Long-term results of peripheral arterial disease rehabilitation. J Vasc Surg. 2004; 39(6): | 186-I 192, doi: 10.1016/j.jvs.2004.01.034, indexed in Pubmed: 15192556 .

3. Jawień A, Grzela T, Migdalski T, et al. Progress in artery surgery in 2004. Practical Medicine. 2005; I: 17-23.

4. Brevetti G, Giugliano $G$, Brevetti L, et al. Inflammation in peripheral artery disease. Circulation. 2010; 122(18): 1862-1875, doi: 10.1161/ CIRCULATIONAHA. 109.9184I7, indexed in Pubmed: 21041698.

5. Gardner A. Exercise Rehabilitation Programs for the Treatment of Claudication Pain. JAMA. 1995; 274(I2): 975, doi: 10.100I/ jama.1995.03530I 20067043.

6. Perrin M, Guex JJ. Edema and leg volume: methods of assessment. Angiology. 2000; 5I(1): 9-12, doi: 10.1 177/000331970005100103, indexed in Pubmed: 10667637.

7. Gardner AW, Killewich LA, Montgomery PS, et al. Response to exercise rehabilitation in smoking and nonsmoking patients with intermittent claudication. J Vasc Surg. 2004; 39(3): 53I-538, doi: 10.1016/j.jvs.2003.08.037, indexed in Pubmed: 14981444.

8. Pasek J, Mucha R, Sieron A. Metabolic syndrome in industry area. Private Office. 2006; 9: 39-43.

9. Davies JA, Bull RH, Farrelly IJ, et al. A home-based exercise programme improves ankle range of motion in long-term venous ulcer patients. Phlebology. 2007; 22(2): 86-89, doi: 10.1258/026835507780346 I78, indexed in Pubmed: 18268857.

10. Pasek J, Opara J, Pasek T, et al. Implications of assessement of Quality of Life in rehabilitation. Physiotherapy. 2007; 15(3): 3-8.

II. Slovut DP, Sullivan TM. Critical limb ischemia: medical and surgical management. Vasc Med. 2008; 13(3): 28I-291, doi: 10.1177/1358863X0809/485, indexed in Pubmed: 18687766.

12. Varu VN, Hogg ME, Kibbe MR. Critical limb ischemia. J Vasc Surg. 20I0; 5I(I): 230-24I, doi: 10.1016/j.jvs.2009.08.073, indexed in Pubmed: 20117502.

13. Gutowski P. Critical limb ischemia at the base of TASC II. OPM. 2009; 4: 18-20.

14. Ambrosetti M, Salerno M, Boni S, et al. Economic evaluation of a short-course intensive rehabilitation program in patients with intermittent claudication. Int Angiol. 2004; 23(2): 108-I I3, indexed in Pubmed: 15507886.

15. Edwards AT, Blann AD, Suarez-Mendez VJ, et al. Systemic responses in patients with intermittent claudication after treadmill exercise. Br J Surg. 1994; 8I(I2): 1738-174I, doi: 10.1002/ bjs. 180081 I 21 I, indexed in Pubmed: 7827927.

16. Devillers C, Vanhooteghem O, de la Brassinne M. Lymphedema and cutaneous diseases. Rev Med Suisse. 2007; 3(136): 2802-2805, indexed in Pubmed: 18183816.

17. Hiatt WR, Regensteiner JG, Wolfel EE, et al. Effect of exercise training on skeletal muscle histology and metabolism in peripheral arterial disease. J Appl Physiol (1985). 1996; 81(2): 780-788, doi: 10.1 I52/jappl. 1996.81.2.780, indexed in Pubmed: 8872646.

18. Lam E, Giswold ME, Moneta GL. Venous and lymphatic disease. Schwartz's Principles of Surgery. 8th ed. New York, NY. 2005: 823-825. 
19. Barwell JR, Davies CE, Deacon J, et al. Comparison of surgery and compression with compression alone in chronic venous ulceration (ESCHAR study): randomised controlled trial. Lancet. 2004; 363(9424): I854-1859, doi: 10.1016/S01406736(04) I6353-8, indexed in Pubmed: $15 \mid 83623$.

20. Partsch $\mathrm{H}$, Blättler W. Compression and walking versus bed rest in the treatment of proximal deep venous thrombosis with low molecular weight heparin. J Vasc Surg. 2000; 32(5): 86I-869, doi: 10.1067/mva.2000.1 10352, indexed in Pubmed: I 1054217.

21. Chandra D, Parisini E, Mozaffarian D. Meta-analysis: travel and risk for venous thromboembolism. Ann Intern Med. 2009; 15I(3): 180-190, doi: 10.7326/0003-48|9-151-3-20090804000129 , indexed in Pubmed: 19581633.

22. Geerts WH, Bergqvist D, Pineo GF, et al. Prevention of venous thromboembolism: American College of Chest Physicians Evidence-Based Clinical Practice Guidelines (8th Edition). Chest. 2008; 133(6 Suppl): 38IS-453S, doi: 10.1378/chest.08-0656, indexed in Pubmed: 1857427I.

23. Lippi G, Favaloro EJ, Cervellin G. Prevention of venous thromboembolism: focus on mechanical prophylaxis. Semin Thromb Hemost. 20I I; 37(3): 237-25I, doi: 10.1055/s-0031-1273088, indexed in Pubmed: 21455858.

24. Haas SK, Hach-Wunderle V, Mader FH, et al. An evaluation of venous thromboembolic risk in acutely ill medical patients immobilized at home: the AT-HOME Study. Clin Appl Thromb Hemost. 2007; 13(I): 7-13, doi: 10.1 177/1076029606296392, indexed in Pubmed: 17164492.

25. Sieroń A, Cierpka L, Rybak Z, Stanek A. Manual of angiology. -medica press, Bielsko-Biała 2009: 106-109.

26. Regensteiner JG, Steiner JF, Hiatt WR. Exercise training improves functional status in patients with peripheral arterial disease. J Vasc Surg. 1996; 23(I): 104-115, doi: 10.1016/s074152।4(05)80040-0, indexed in Pubmed: 8558725.

27. McDermott MM, Ferrucci L, Guralnik JM, et al. The ankle-brachial index is associated with the magnitude of impaired walking endurance among men and women with peripheral arterial disease. Vasc Med. 2010; 15(4): 25I-257, doi: I0.1 177/1358863X10365 I8I, indexed in Pubmed: 205। I 294.

28. Taylor-Piliae RE, Fair JM, Varady AN, et al. Ankle brachial index screening in asymptomatic older adults. Am Heart J. 201 I; 161(5): 979-985, doi: 10.1016/j.ahj.2011.02.003, indexed in Pubmed: 21570532.

29. Tomkowski WZ, Paje D. Diagnosis and treatment of venous thromboembolic disease. OPM. 2009; 4: 32-34.

30. Naylor AR. Does the modern concept of ,best medical therapy' render carotid surgery obsolete? Eur J Vasc Endovasc Surg. 2004; 28(5): 457-46I, doi: 10.1016/j.ejvs.2004.07.022, indexed in Pubmed: 15465365.

31. Prinssen M, Wixon CL, Buskens E, et al. Surveillance after endovascular aneurysm repair: diagnostics, complications, and associated costs. Ann Vasc Surg. 2004; 18(4): 42I-427, doi: 10.1007/s 100 16-004-0036-3, indexed in Pubmed: 15108054.

32. Pasek J, Wołyńska-Ślężyńska A, Ślężyński J, et al. Significance of corrective swimming and water exercises in physiotherapy. Physiotherapy. 2009; 17(I), doi: 10.2478/v10109-009-0042-7.

33. Killewich LA, Macko RF, Montgomery PS, et al. Exercise training enhances endogenous fibrinolysis in peripheral arterial disease. J Vasc Surg. 2004; 40(4): 74I-745, doi: 10.1016/j. jvs.2004.07.030, indexed in Pubmed: 15472603.
34. Crowther RG, Spinks WL, Leicht AS, et al. Effects of a longterm exercise program on lower limb mobility, physiological responses, walking performance, and physical activity levels in patients with peripheral arterial disease. J Vasc Surg. 2008; 47(2): 303-309, doi: 10.1016/j.jvs.2007.10.038, indexed in Pubmed: 18241753.

35. Hamburg NM, Balady GJ. Exercise rehabilitation in peripheral artery disease: functional impact and mechanisms of benefits. Circulation. 201 I; 123(I): 87-97, doi: 10.1161/CIRCULATIONAHA. 109.881888 , indexed in Pubmed: 21200015.

36. Chierichetti F, Mambrini S, Bagliani A, et al. Treatment of Buerger's disease with electrical spinal cord stimulation - review of three cases. Angiology. 2002; 53(3): 34I-347, doi: 10.1177/0003319702053003/3, indexed in Pubmed: I2025923.

37. Riccioni C, Sarcinella R, lzzo A, et al. Rehabilitative treatment in peripheral artery disease: protocol application and follow-up. Minerva Cardioangiol. 2010; 58(5): 55I-565, indexed in Pubmed: 20948502.

38. Minar E. Peripheral arterial occlusive disease. Vasa. 2007; 36(3): 155-164, doi: 10.1024/030I-1526.36.3.155, indexed in Pubmed: 1801927I.

39. Regensteiner JG, Steiner JF, Hiatt WR. Exercise training improves functional status in patients with peripheral arterial disease. J Vasc Surg. 1996; 23(I): 104-1 15, doi: 10.1016/s074152।4(05)80040-0, indexed in Pubmed: 8558725.

40. Campbell B. Varicose veins and their management. BMJ. 2006; 333(7562): 287-292, doi: 10.1 |36/bmj.333.7562.287, indexed in Pubmed: 16888305.

4I. Aldrich D, Hunt DP. When can the patient with deep venous thrombosis begin to ambulate? Phys Ther. 2004; 84(3): 268-273, indexed in Pubmed: 14984299.

42. Kahn SR, Shrier I, Kearon C. Physical activity in patients with deep venous thrombosis: a systematic review. Thromb Res. 2008; 122(6): 763-773, doi: 10.1016/j.thromres.2007.10.01।, indexed in Pubmed: 18078981 .

43. Warren AG, Brorson H, Borud LJ, et al. Lymphedema: a comprehensive review. Ann Plast Surg. 2007; 59(4): 464-472, doi: 10.1097/0I.sap.0000257|49.42922.7e, indexed in Pubmed: 17901744 .

44. Lee B, Andrade M, Bergan J, et al. International Union of Phlebology. Diagnosis and treatment of primary lymphedema. Consensus document of the International Union of Phlebology (IUP)2009. Int Angiol. 2010; 29(5): 454-470, indexed in Pubmed: 20924350.

45. Gloviczki P, Comerota AJ, Dalsing MC, et al. Society for Vascular Surgery, American Venous Forum. The care of patients with varicose veins and associated chronic venous diseases: clinical practice guidelines of the Society for Vascular Surgery and the American Venous Forum. J Vasc Surg. 20I I; 53(5 Suppl): 2S-48S, doi: 10.1016/j.jvs.2011.01.079, indexed in Pubmed: 21536172 .

46. Kolluri R. Compression therapy for treatment of venous disease and limb swelling. Curr Treat Options Cardiovasc Med. 20I I; 13(2): 169-178, doi: 10.1007/s||936-0||-0||4-0, indexed in Pubmed: 21286870.

47. Junkins-Hopkins JM. Biologic dressings. J Am Acad Dermatol. 20I I; 64(I): e5-e7, doi: 10.1016/j.jaad.2010.09.729, indexed in Pubmed: 21 167402. 
48. de Godoy JM, Braile DM, Perez FB, et al. Effect of walking on pressure variations that occur at the interface between elastic stockings and the skin. Int Wound J. 2010; 7(3): 191-193, doi: 10.1 I I I/j. I742-48IX.2010.00673.x, indexed in Pubmed: 20602649.

49. Mosti G, Partsch H. Inelastic bandages maintain their hemodynamic effectiveness over time despite significant pressure loss. J Vasc Surg. 2010; 52(4): 925-931, doi: 10.1016/j.jvs.2010. 04.08I, indexed in Pubmed: 20620002.

50. Szolnoky G, Lakatos B, Keskeny T, et al. Intermittent pneumatic compression acts synergistically with manual lymphatic drainage in complex decongestive physiotherapy for breast cancer treatment-related lymphedema. Lymphology. 2009; 42(4): I88-194, indexed in Pubmed: 20218087.

5I. Tan IC, Maus EA, Rasmussen JC, et al. Assessment of lymphatic contractile function after manual lymphatic drainage using near-infrared fluorescence imaging. Arch Phys Med Rehabil. 20II; 92(5): 756-764.el, doi: 10.1016/j.apmr.2010.12.027, indexed in Pubmed: 21530723.

52. Stahel HU. Manual lymph drainage. Curr Probl Dermatol. 1999; 27: 148-152, doi: 10.1159/000060640, indexed in Pubmed: 10547739.

53. Asdonk J. Effectiveness, indications and contraindications of manual lymph drainage therapy in painful edema. Z Lymphol. 1995; 19(1): 16-22, indexed in Pubmed: 7571790.
54. Pasek J, Cieślar G, Stanek A, et al. Health resort treatment a new chance for treatment of diseases of peripheral vessels? Acta Angiol. 2010; 16: 99-113.

55. Hiatt WR, Regensteiner JG, Wolfel EE, et al. Effect of exercise training on skeletal muscle histology and metabolism in peripheral arterial disease. J Appl Physiol (1985). 1996; 8I (2): 780-788, doi: 10.1 I52/jappl. 1996.81.2.780, indexed in Pubmed: 8872646.

56. Voronov NE, Grigor'ev II. Effectiveness of sanatorium-health resort treatment and the need for it in patients with diseases of the peripheral vessels. Vopr Kurortol Fizioter Lech Fiz Kult. 1974(I): 34-38, indexed in Pubmed: 4282436.

57. Pasek J, Sieron A. Ledtherapy. Practical Physiotherapy and Rehabilitation. 201 I; 13: 52-55.

58. Pasek J, Cieslar G, Pasek T, et al. The treatment of polarized light - New chance of light therapy? Balneol Pol. 2008; 2(I I 2): 93-9.

59. Sieroń A, Pasek J, Mucha R. Magnetotherapy. Rehab w Prakt. 2006; 3: 29-32.

60. Pasek J, Mucha R, Sieron A. Magnetostimulation - the new form in medicine and rehabilitation. Physiotherapy. 2006; 14(4): 3-8.

61. Sieron A, Pasek J, Mucha R. Magnetic fields and light therapy in medicine and rehabilitation - magnetoledtherapy. Balneol Pol. 2007; I(I07): I-7. 